\title{
A Case Study of Non-English Major College Students' Motivation in English Language Learning
}

\author{
Meilan Jin \\ College of Foreign Languages, Yanbian University, Yanji City, China \\ Email: kml-0322@163.com
}

Received 27 February 2014; revised 2 April 2014; accepted 9 April 2014

Copyright (C) 2014 by author and Scientific Research Publishing Inc.

This work is licensed under the Creative Commons Attribution International License (CC BY). http://creativecommons.org/licenses/by/4.0/

\section{c) (i) Open Access}

\begin{abstract}
Motivation is considered as a key feature in the success of language learning and has great effect on the efficiency and productivity of English language teaching. And a lot of considerable researches and investigations have been done on Chinese college students' motivation to learn English. Most researches like to value instrumental aspects as the major type for college students' learning English in Chinese context while integrative motivation is often neglected. In this study, 300 college students are employed to further explore students' instrumental motivation and integrative motivation and the data analysis of the study somehow shows difference from others, supporting that college students do have expectation and strong integrative motivation toward English language learning and recommendations are offered to the teachers to develop college students' integrative motivation in English language teaching, suggesting focusing on cultural education in particular.
\end{abstract}

\section{Keywords}

Case Study, College English Learning and Teaching, Instrumental Motivation, Integrative Motivation, Cultural Education

\section{Introduction}

Learning and mastering a foreign language becomes a basic requirement for the citizens in the $21^{\text {st }}$ century and Chinese College English Curriculum Requirements (CCECR) stresses that College English is not only a language course that provides basic knowledge about English, but also a capacity enhancement course that helps students broaden their horizons and learn about different cultures in the world, which clearly indicates that col- 
lege English teaching should be aimed at cultivating their intercultural communicative competence as well as developing students' English proficiency. However, it seems that college English teaching efficiency and productivity does not correspond with CCECR. Even though most of the college students learn English as a compulsory course, many of them show low motivation in English study and even completely give up learning English especially after passing College English test-band 4 (CET-4), which made me have to rethink English teaching orientation and the motivation of both students' English language learning (ELL) and teachers' English language teaching (ELT), in particular.

Wang Chuming (1989) acknowledged that motivation was considered as one of the significant factors impacting foreign language learning. For Chinese students, instrumental motivation is the main type in English foreign language learning. The studies of Hua Huifang (1998) point out that almost $80 \%$ students' motivation is certificate motivation, and it is concluded in some studies (Hua, 2000; Shi, 2000) that integrative motivation is not very important for English learning in Chinese context and "certificate motivation" is the major type, which infers that certificate motivation considered as a kind of instrumental motivation is more significant than integrative motivation for Chinese English learners. And there is a growing consensus that instrumental motivation or orientation perhaps should have a greater prominence in foreign language environment (Li, 2007; Xiang, 2010) and that only a few of non-English majors just have the integrative motivation in ELL and most Chinese learners are not learning English for international communication but for social and economic mobility. As is shown, it's pervasively believed that the instrumental orientation is the major Chinese learners' ELL motivation and that it should be, which might have been misleading college students' ELL and teachers' ELT orientation.

Brown (2000) maintains that both integrative motivation and instrumental motivation are not necessarily mutually exclusive. Based on the motivation theory, the study intends to further explore current college non-English major students' instrumental and integrative motivation in ELL and support that college students do have expectation and integrative motivation toward ELL and concludes that it is a matter of great urgency to cultivate students' integrative motivation in foreign language learning (FLL) in order to develop their intercultural communicative capacity and keep their long-term learning sustainable.

\section{Review of the Definition of Motivation}

Amid the last decade, with increasing attention paid to the roles of the learners in the process of language learning, there is a general consensus in the literature that motivation is one of the key learner characteristics. Many teachers and researchers have done a lot of researches on the role of motivation and explored it from diverse perspectives such as behaviorism, cognitive psychology and sociology, which are all related and add to our understanding of what motivates students. Brown (1980) has made a statement that motivation is possibly the most often used catch-all term in explaining the success or failure of almost any complicated tasks. Deci and Ryan (1985) in their self-determination theory argue that different subtypes of motivation, i.e., intrinsic and extrinsic motivation, can be shown along a continuum depending on the degree of self-determination. Crooks and Schmidt (1991) think it as the learner's orientation regarding the goal of learning a second language and suggest that motivation to learn a language has both internal and external factors. Dörnyei (2009) maintains that motivation is one of the most important concepts in psychology and language education, which is commonly used to explain learners' success and failure in learning.

However, it is the work of Gardner and his associates that has heavily influenced the research on motivation in SLA. Gardner (1972) has suggested that motivation is considered as a central element along with language proficiency in determining the success in the process of learning other language. He suggests that motivation is influenced by two orientations to language learning which are integrative orientation and instrumental orientation. Gardner et al. (1977) define them as follows: Integrative reasons are defined as those that indicate an interest in learning the language in order to meet and communicate with members of the second language community. Instrumental reasons refer to those reasons, which stress the pragmatic aspects of learning the second language, without any particular interest in communicating with the second language community.

With instrumental motivation, the purpose of language acquisition is more practical, such as meeting a requirement for school or college graduation, seeking for a job, reading technical and scientific materials, doing translation works, doing some traveling etc. While both integrative and instrumental reasons are essential elements of success, it is integrative motivation that has been found to sustain long-term success sustainable when learning a second language (Taylor, 1977; Ellis, 1997; Crookes, 1991). It is thought that students who are most 
successful when learning a target language are those who like the people that speak the language, admire the culture and have a desire to become familiar with or even integrate into the society in which the language is used (Falk, 1978).

As is shown, various definitions of motivation have been suggested over the decades and since researchers define motivation from different perspectives, it has been classified into various kinds: such as internal and external, integrative and instrumental, intrinsic and extrinsic, etc. The present study mainly focuses on "instrumental orientation" and "integrative orientation" and highlights the latter.

\section{Research Method}

\subsection{Participants}

The participants are 300 freshmen from 8 classes of 2012, YBU. In order to make the questionnaire more reliable and accurate, the study employs the participants from different level classes-4 lower intermediate classes (Group A, N-142) and 4 high-level classes (Group B, N-158), which were divided after the students were assessed at the beginning of the $1^{\text {st }}$ semester in 2012. At the time of data collection, most of them had been learning English as a foreign language in China at least for 10 years, while they have uneven and various personalities, goals and levels of motivation. The respective percentage of passing CET-4 for each group after students first participated in the CET- 4 exam in December, 2012 is $4.2 \%$ for Group A (only 4 students passed CET- 4 ) and $65.8 \%$ for Group B (104 students did). Therefore, the subjects selected from both lower intermediate classes and high-level classes for investigation are quite representative to assure the reliability and accuracy of the study.

\subsection{Design and Procedures}

The main purpose of the investigation is to find whether and how motivation factors, especially integrative factors are connected with non-English major college students' ELL. Two data collection instruments were used in the study: questionnaire for students and CET-4 grades reported by students themselves. The essential questionnaire, which consists of 10 typical items, relevant to instrumental and integrative motivation in EFL, was designed on the basis of previous motivation theory and what we have to discuss. The students were required to read each item and choose the most situation applied to them. Among 6 reactions attached to each item with strongly agree (SA), agree (A), possibly agree (PA), possibly disagree (PD), disagree (D), and strongly disagree (SD), only first two reactions, SA and A were adopted to analyze students' positive motivation. The questionnaire was finished over two weeks in June, 2013 and the data was calculated with the assistance of Microsoft Excel.

\section{Results and Discussion}

\subsection{Percentage of Instrumental Orientation}

As Table 1 shows, among the five items of instrumental orientation, first two items, "to travel around or get more information about the world" (72\%), and "to get a satisfying job" (68.6\%) are the most important reasons for college students to learn English and nearly $50.4 \%$ of the students show instrumental intensity in the item "to go abroad for academic study", and the percentage of "to operate computers conveniently" is $46.7 \%$. All of this can imply that students have clear instrumental motivation of ELL. In particular the percentage of $68.6 \%$ for "to get a satisfying job" is pretty reasonable for the college students who feel under stress of career choices. However, ironically, there is exception with the lowest percentage of "to pass exams like CET-4" reaching only $24.3 \%$. In view of regarding "certificate motivation" as one of the major factors for Chinese college students to learn English, it cannot be a bigger reverse.

\subsection{Percentage of Integrative Orientation}

The items from 8 to 12 in Table 2 are mainly designed to investigate students' integrative orientation. As is shown in Table 2, to the item "To watch movies or read works in English", "To talk with various of people by using English", "To communicate freely with English native speakers", "To better understand the society and culture in English speaking countries" and "To get satisfaction due to English proficiency", SA and A percentage 
Table 1. Percentage of instrumental orientation (N-300).

\begin{tabular}{lcccccc}
\hline \multicolumn{1}{c}{ Items } & SA & A & PA & PD & D & SD \\
\hline 1) To travel around or get more information about the world & $38.0 \% 114$ & $34 \% 102$ & $20 \% 60$ & $4 . \% 12$ & $2 \% 6$ & $2 \% 6$ \\
2) To find a satisfying job & $26.3 \% 79$ & $42.3 \% 127$ & $20.7 \% 62$ & $4.3 \% 13$ & $3.8 \% 11$ & $2.7 \% 8$ \\
3) To go abroad for academic study & $22.7 \% 68$ & $27.7 \% 83$ & $23.7 \% 71$ & $12.3 \% 37$ & $10.7 \% 32$ & $3 \% 9$ \\
4) To operate computers conveniently & $13.7 \% 41$ & $33 \% 99$ & $23.7 \% 71$ & $13.7 \% 41$ & $12.7 \% 38$ & $3.3 \% 10$ \\
5) To pass the exams (CET-4/CET6 etc.) & $6 \% 18$ & $18.3 \% 55$ & $20.7 \% 62$ & $18.7 \% 56$ & $17.3 \% 52$ & $19 \% 57$ \\
\hline
\end{tabular}

Table 2. Percentage of integrative orientation (N-300).

\begin{tabular}{|c|c|c|c|c|c|c|}
\hline Items & SA & A & PA & PD & $\mathrm{D}$ & $\mathrm{SD}$ \\
\hline 6) To watch movies or read works in English & $39.7 \% 119$ & $30.7 \% 92$ & $17.7 \% 53$ & $8.7 \% 26$ & $2.7 \% 8$ & $1 \% 3$ \\
\hline 7) To talk with various of people by using English & $32.7 \% 98$ & $36 \% 108$ & $19.4 \% 58$ & $5.7 \% 17$ & $3 \% 9$ & $3.3 \% 10$ \\
\hline 8) To communicate freely with English native speakers & $36 \% 108$ & $30.3 \% 91$ & $18.5 \% 54$ & $10.3 \% 31$ & $2 \% 6$ & $4.3 \% 13$ \\
\hline $\begin{array}{l}\text { 9) To better understand the society and culture } \\
\text { in English speaking countries }\end{array}$ & $33.7 \% 101$ & $32 \% 96$ & $20.4 \% 61$ & $10.7 \% 32$ & $2 \% 6$ & $4.3 \% 13$ \\
\hline 10) To get satisfaction due to English proficiency & $31.3 \% 94$ & $32 \% 96$ & $18.3 \% 55$ & $12 . \% 36$ & $4.3 \% 13$ & $2 \% 6$ \\
\hline
\end{tabular}

is $70.4 \%, 68.7 \%, 66.3 \%, 65.7 \%$ and $63.3 \%$ respectively and its average value is $14.5 \%$ higher than that of instrumental orientation (52.4\%), which suggests that students seem to have stronger integrative orientation in ELL, different from prior studies considering that only a few students have integrative motivation in ELL.

\subsection{Percentage of Comparison of Instrumental Orientation of Group A and Group B}

In order to get precise data to support the study, comparison of students' motivation between GA and GB to learn English is conducted. As is shown in Table 3, percentage of "To go abroad for academic study "is 50\% for GA and 51\% for GB", and "To operate computers conveniently" is 48\% for GA and 46\% for GB, which appears less mean difference. However, the percentage of "pass the exams like CET-Band 4" is 33\% for GA and 17\% for GB, "To find a satisfying job" is $72 \%$ for GA and $66 \%$ for GB, and "To travel around or get more information about the whole world" is $67 \%$ for GA and $77 \%$ for GB respectively, implying that low achievers from GA have more powerful instrumental orientation under stress to pass the exams to get the certificate or to get a better job.

\subsection{Percentage of Comparison of Integrative Orientation of Group A and Group B}

SA and A percentage of comparison of "To watch movies or read works in English", "To talk with various of people by using English", "To communicate freely with English native speakers", "To better understand the society and culture in English speaking countries" and "To get satisfaction due to English proficiency", shows obvious mean difference with GB holding higher percentage in every item, which is $15 \%, 18 \%, 15 \%, 24 \%$ and $23 \%$ higher respectively. Undoubtedly, Table 4 supports the conclusion made by previous researches that integrative motivation correlates positively with motivational intensity and interest in English and the students with integrative motivation show much more interest in the culture, the people and other aspects of the target language and more successful in learning target language than those who are instrumentally motivated. However, with average value of $56.8 \%$, students from GA also show a little higher integrative orientation than instrumental orientation whose average value is $54 \%$ in accordance with the data result.

As a whole, the thought that for most of the college non-English majors, they study English because of instrumental motivation or certificate motivation is somewhat subjective and incomplete without considering students' implicit necessity—students' inner, intrinsic, and integrative factors. It's true that a large number of students learn English to pursue their own goals, such as getting good grades in the exams, passing the CET-4, and getting good jobs after graduation; it's true that most students have no more interest in ELL and even give up 
Table 3. Comparison of instrumental orientation of Group A (N-142) and Group B (N-158).

\begin{tabular}{|c|c|c|c|}
\hline Items & Group & SA & A \\
\hline \multirow{2}{*}{ 1) To travel around or get more information about the whole world } & GA (142) & $37 \%(52)$ & $30 \%(43)$ \\
\hline & GB (158) & $39 \%(62)$ & $38 \%(59)$ \\
\hline \multirow{2}{*}{ 2) To find a satisfying job } & GA (142) & $31 \%(44)$ & $41 \%(58)$ \\
\hline & GB (158) & $22 \%(35)$ & $44 \%(69)$ \\
\hline \multirow{2}{*}{ 3) To go abroad for academic study } & GA (142) & $21 \%(30)$ & $29 \%(41)$ \\
\hline & GB (158) & $24 \%(38)$ & $27 \%(42)$ \\
\hline \multirow{2}{*}{ 4) To operate computers conveniently } & GA (142) & $15 \%(21)$ & $33 \%(47)$ \\
\hline & GB (158) & $13 \%(20)$ & $33 \%(52)$ \\
\hline \multirow{2}{*}{ 5) To pass the exams (CET-4/ CET6 etc.) } & GA (142) & $11 \%(15)$ & $22 \%(31)$ \\
\hline & GB (158) & $2 \%(3)$ & $15 \%(24)$ \\
\hline
\end{tabular}

Table 4. Comparison of integrative orientation of Group A (N-142) and Group B (N-158).

\begin{tabular}{|c|c|c|c|}
\hline Items & Group & SA & A \\
\hline \multirow{2}{*}{ 6) To watch movies or read works in English } & GA (142) & $33 \%(47)$ & $30 \%(42)$ \\
\hline & GB (158) & $46 \%(72)$ & $32 \%(50)$ \\
\hline \multirow{2}{*}{ 7) To talk with various of people by using English } & GA (142) & $31 \%(44)$ & $28 \%(40)$ \\
\hline & GB (158) & $34 \%(54)$ & $43 \%(68)$ \\
\hline \multirow{2}{*}{ 8) To communicate freely with English native speakers } & GA (142) & $28 \%(40)$ & $30 \%(43)$ \\
\hline & GB (158) & $43 \%(68)$ & $30 \%(48)$ \\
\hline \multirow{2}{*}{ 9) To better understand the society and culture in English speaking countries } & GA (142) & $26 \%(37)$ & $27 \%(39)$ \\
\hline & GB (158) & $41 \%(64)$ & $36 \%(57)$ \\
\hline \multirow{2}{*}{ 10) To get satisfaction due to English proficiency } & GA (142) & $26 \%(37)$ & $25 \%(36)$ \\
\hline & GB (158) & $36 \%(57)$ & $38 \%(60)$ \\
\hline
\end{tabular}

learning English as long as they pass CET-4; it's true that most learners really have few opportunities to communicate directly with English native speakers in Chinese context. However, it is subjective and unreasonable to conclude they don't have much interest in the culture, the people, and other aspects of the target language. As the survey reveals, many more students do express interest in learning English, wish to meet and communicate with members of the English language community, and they are passionate about target language culture, which imply their motivation to learn English does not only arise for instrumental orientation. Apart from the results of the motivation questionnaire, observing the students through the classroom teaching in which more cultural factors are involved also shows that they are really interested in the target language culture. There is no doubt that students are primarily motivated by instrumental factors in Chinese context but we have to realize that it is because of certain social and educational backgrounds in China.

In the process of the survey, the doubt emerged that motivation of learning English like "to travel around or get more information about the world" is somewhat different from such instrumental factors as entering a college, passing the exam, or getting a better job, and so on, even though previous researchers identified it as instrumental motivation and so it is. Cognitive approaches suggest that students can be motivated to perform well, not only because of rewards such as grades or praise, but because of factors such as interest, curiosity, the need to obtain information or solve a problem, or the desire to understand (Kenneth, 2005) Therefore, it may be better to treat the high intensity of "to travel around or get more information about the whole world" as the demonstra- 
tion of students' intrinsic interest in ELL, as Noels et al. (2000) put it, the activity is enjoyable and satisfying to do. In addition, for most people, except for the relaxation from routines and the feast for the eyes, one of the purposes to travel or get more information about the world may be to broaden their horizons, enrich their experiences and get perception of life, especially by touching local customs and habits, which suggests they would like to become familiar with or even integrate into the different cultures and society. Thus, it may be feasible to perceive such motivation to learn English as "to travel around or get more information about the world" as integrative orientation. Broadly speaking, the data results support that Chinese college and university students have powerful integrative orientation in center.

\section{Conclusion and Recommendation}

\subsection{Conclusion}

Global age or world is the hot concept of educational world. We have to realize that with the development of social economy, living in an age of global information, college and university students have been broadening their outlook and expecting to know and learn things outside of their special and limited areas, and this kind of trend of motivation is meaningful to guide ELT. Based on the survey, I'd like to draw conclusions as follows:

Most students are aware of the important role of English in both life and academic filed, and have clear and strong instrumental and integrative motivation in learning English.

In accordance with the survey, students, regardless of learning in high level classes or lower intermediate classes, display strong integrative intensity in ELL, which is not lying around on the ground but needs discovering, excavating and cultivating.

The prior conclusion that instrumental motivation is Chinese college students' major orientation to learn English sounds somewhat subjective and unreasonable, lack of insight to understand the complex situations where students have to. The situation where students' are primarily motivated by instrumental factors is not caused by students' will but is partially imposed on the students in certain social and educational backgrounds in China. What's more, instrumental motivation like "to learn English is to travel around or get more information about the world" more or less displays integrative orientation.

For the students, the lower their grades are, the stronger their instrumental orientation is under stress to pass the exams to get the certificate or to get a better job, but it has less to do with students' holding integrative orientation.

There are still approximately $30 \%$ of the students lack of the real awareness of English learning who need to be guided. And even though more than half of the students show integrative orientation in ELL, it doesn't mean they make full use of it in ELL as is discussed in previous studies.

With only 10 items utilized in the questionnaire and only 300 students from Yanbian University employed to complete the questionnaire, the present study may not fully represent all Chinese non-English majors. Despite this limitation, the results of the study support that we should acknowledge students' integrative motivation and value the motivation toward ELL and cultivate it. In addition, the fact that cannot be missed is that there is a very big gap between the development of English Education of metropolitan cities and that of Yanji City where Yanbian University is located, without even decent remedial or additional English class for TOEFL or IELTS. In other words, since students from YBU have such strong integrative motivation to learn English, let alone those studying in colleges or universities in other areas under the influence of globalization of the English language. All these findings cannot be more important and meaningful to guide ELT.

As a whole, both instrumental motivation and integrative motivation are nothing less in Chinese context. However, focusing only on what is most easily measured or on immediate practical impact is to miss the deeper point. The point is how to support students' integrative motivation and let it come into play, leading to developing students' intercultural communicative competence and their long-term learning being sustainable where the learners are supplied with no chances to make most of target language and no opportunities to keep interactions with members of the target language.

\subsection{Recommendation}

In the light of globalization of the English language, the success of ELT does not only depend on improving students' knowledge and skills of English language but also developing their cultural capacity and intercultural 
communicative competence, which implies that cultivating students' integrative motivation is a matter of great urgency in foreign language teaching. To promote genuine cultural awareness and international understanding and to ensure the efficiency and productivity of college English teaching, teachers are supposed to keep themselves abreast of new research and knowledge in the teaching of language acquisition and be prepared with sufficient cultural knowledge of the target language. The below are the recommendations offered to the teachers to develop students' integrative motivation in ELT.

Firstly, teachers should raise their own awareness of the relationship of culture and language and try to improve their awareness of culture teaching, which is to absolutely affect students' integrative motivation orientation. Secondly, teachers should continue to improve students' awareness of learning English and let students understand English learning is a life style rather than simply being a preparation for passing examination. Thirdly, teachers should enhance students' learning autonomy, not only in classroom but also after class by designing and assigning lots of available tasks so that students have a number of opportunities to use English, for the more they use English in their everyday lives, the more quickly their acquisition and proficiency improve and so do in return their confidence and autonomy in ELL. Fourthly, teachers should create a strong classroom community where students use the target language to learn, touch and share the culture, by designing and/or selecting teaching materials that are international and inclusive in scope, which is available enough for the teachers to obtain with the development of modern science and technology.

In a word, there should be changes in teaching philosophy. Without changes in teaching philosophy and a shift from instrument-centered pattern, in which knowledge of the language and skills are imparted by the teacher in class, to the integration-centered pattern, in which both language teaching and culture teaching are connected with each other, our students would ever have to remain as instrument-oriented learners, which means it would be unachievable to develop students' intercultural communicative competence and to keep their long-term learning being sustainable.

\section{References}

Brown, H. D. (1980). The Optional Model of SLA. TESOL Quarterly, 14, 64-157.

Brown, H. D. (2000). Principles of Language Learning and Teaching (4th ed.). New York: Prentice Hall.

Crookes, G., \& Schmidt, R. W. (1991). Motivation: Reopening the Research Agenda. Language Learning, 41, 469-512. http://dx.doi.org/10.1111/j.1467-1770.1991.tb00690.x

Deci, E. L., \& Ryan, R. M. (1985). Intrinsic Motivation and Self Determination in Human Behaviour. New York: Plenum Press. http://dx.doi.org/10.1007/978-1-4899-2271-7

Dörnyei, Z. (2009). The L2 Motivational Self System. In Z. Dornyei, \& E. Ushioda (Eds.) Motivation, Language Identity and the L2 Self, Clevedon: Multilingual Matters.

Ellis, R. (1997). The Study of Second Language Acquisition. Oxford: Oxford University Press.

Falk, J. (1978). Linguistics and Language: A Survey of Basic Concepts and Implications (2nd ed.). New York: John Wiley and Sons.

Gardner, R. C., \& Lambert, W. E. (1972). Attitudes and Motivation in Second Language Learning. Rowley, MA: Newbury House Publishers.

Gardner, S., \& Brunet, G. R. (1977). Intensive Second Language Study: Effects on Attitudes, Motivation and French Achievement. Language Learning, 27, 243-261. http://dx.doi.org/10.1111/j.1467-1770.1977.tb00121.x

Henson, K. T., \& Eller, B. F. (2005). Educational Psychology for Effective Teaching. Beijing: Foreign Language Teaching and Research Press.

Hua, H. F. (1998). Discussion on the Study of the Motivation and Strategies of Learning English. Journal of the Foreign Language World, 3.

Hua, H. F. (2000). A Study on the Motivation and Strategies of Learning English. Journal of the Foreign Language World, 3 , 44-47.

Li, J. W. (2007). A Case Study of Changing Motivation in Foreign Language Learning. Teaching English China, 3, 61.

Noels, K. A., Pelletier, L. G., Clement, R., \& Vallerand, R. J. (2000). Why Are You Learning a Second Language? Motivational Orientations and Self-Determination Theory. Language Learning, 50, 57-85.

http://dx.doi.org/10.1111/0023-8333.00111

Shi, Y. Z. (2000). A Survey of College Students' Learning English. Foreign Language Teaching, 4, 8-11. 
Taylor, D. M., Meynard, R., \& Rheault, E. (1977). Threat to Ethnic Identity and Second-Language Learning. In H. Giles (Ed.), Language, Ethnicity and Intergroup Relations (pp. 99-118). London and New York: Academic Press.

Wang, C. M. (1989). Chinese Students' Learning Patterns of Foreign Languages. Foreign Language Teaching and Research, 4.

Xiang, H. B. (2010). Motivation Theories and Its Inspirations in College English Teaching. Master Dissertation, Qingdao: Qingdao University of Science and Technology. 